\title{
Use of Biphasic Continuous Positive Airway Pressure in Premature Infant with Cleft Lip-Cleft Palate
}

\author{
Lovya George, MBBS ${ }^{1}$ Sunil K. Jain, MD, FAAP² \\ ${ }^{1}$ Department of Pediatrics, University of Texas Medical Branch, \\ Galveston, Texas \\ 2 Division of Neonatology, Department of Pediatrics, University of \\ Texas Medical Branch, Galveston, Texas \\ Am J Perinatol Rep 2015;5:e83-e84.
}

\begin{abstract}
Address for correspondence Lovya George, MBBS, Department of Pediatrics, University of Texas Medical Branch, 301 University Blvd, Galveston, TX 77555-0354 (e-mail: logeorge@utmb.edu).
\end{abstract}

\begin{abstract}
Keywords

- noninvasive ventilation

- premature infant

- cleft lip-cleft palate

- BP-NCPAP

Preterm infants (PIs) often require respiratory support due to surfactant deficiency. Early weaning from mechanical ventilation to noninvasive respiratory support decreases ventilation-associated irreversible lung damage. This wean is particularly challenging in Pls with cleft lip and cleft palate due to anatomical difficulties encountered in maintaining an adequate seal for positive pressure ventilation. PI with a cleft lip and palate often fail noninvasive respiratory support and require continued intubation and mechanical ventilation. We are presenting the first case report of a PI with cleft lip and palate who was managed by biphasic nasal continuous positive airway pressure.
\end{abstract}

\section{Case}

An African American female infant was born at 26 weeks of gestation by vaginal delivery with birth weight $670 \mathrm{~g}$ at the University of Texas Medical Branch, Galveston. Pregnancy was complicated by oligohydramnios due to prolonged rupture of membranes, preterm labor, and marijuana use. At birth, the infant was noted to have right-sided cleft lip with complete absence of palate on the right side. Infant was intubated, received surfactant for respiratory distress syndrome, and transferred to the Neonatal Intensive Care Unit where she was ventilated with high-frequency oscillation ventilation (HFOV). No other congenital anomalies were noted.

On day 5 , the infant was stable on the HFOV at a frequency of $6 \mathrm{~Hz}, 21 \% \mathrm{Fio}_{2}$, MAP of 8 , and amplitude 19 . She was extubated to biphasic nasal continuous positive airway pressure (BP-NCPAP) at pressures $9 / 6$ and a rate of 20 . She was also started on caffeine. We were unable to maintain adequate pressures and the infant required re-intubation and HFOV due to repeated apnea and desaturations secondary to apnea of prematurity. On day 23 , the infant was stable on conventional mechanical ventilator at pressures $20 / 5$, rate of 20 , pressure support of 7 , and inspiratory time $0.35 \mathrm{~s}$. She was given a dose of dexamethasone and was successfully extubated to BP-NCPAP of $8 / 5$ followed by gradual weaning of respiratory support ( - Fig. 1). BP-NCPAP was delivered by the Infant Flow ${ }^{\circledR}$ SiPAPTM (Viasys Healthcare, Yorba Linda, CA, USA) by alternating SiPAP mask and nasal prongs.

This patient was maintained on BP-NCPAP for almost one month before successfully weaning to nasal cannula on day 42 and finally to room air at 37 weeks and discharged home at 40 weeks corrected gestational age (CGA). Her head ultrasound on day 7 and MRI of head prior to discharge were within normal limits for gestation.

She is being followed in our neonatal follow-up clinic for neurodevelopmental outcome, plastic surgery for cleft lip and palate repair, and chronic care team for feeding and nutrition. At 6 months CGA, her development assessed by Gesell development scale was within normal limits.

\section{Discussion}

Development of noninvasive respiratory support like NCPAP and BP-NCPAP has improved the outcome of preterm infants (PIs) ${ }^{1}$ by allowing earlier wean from mechanical ventilation, thus limiting ventilator-associated lung injury. ${ }^{2}$ NCPAP results in progressive alveolar recruitment received

March 26, 2014 accepted after revision July 22, 2014 published online April 27, 2015
DOI http://dx.doi.org/ 10.1055/s-0034-1396449. ISSN 2157-7005.
Copyright $\odot 2015$ by Thieme Medical Publishers, Inc., 333 Seventh Avenue, New York, NY 10001, USA. Tel: +1(212) 584-4662.
License terms

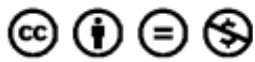




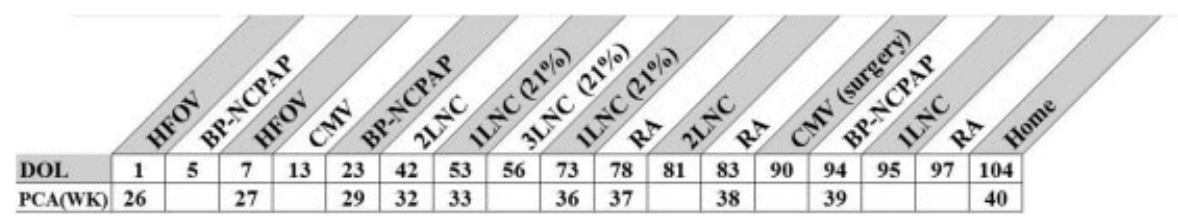

Fig. 1 Timeline of weaning respiratory support.

and inflation of collapsed alveoli by continuous distending pressure. The effectiveness of NCPAP depends on a tight seal. As neonates are obligate nose breathers, they spontaneously form a seal between the palate and the tongue. In infants with a cleft lip and palate, NCPAP is not as effective because these neonates cannot form the seal between the tongue and palate. ${ }^{1}$ BP-NCPAP prevents alveolar collapse and decreases work of breathing by recruiting functional residual capacity by cycles between upper and lower level pressures. In contrast to NCPAP, BP-NCPAP also has a set rate which is helpful in apnea of prematurity which was the primary cause of initial extubation failure in this infant. McMahon et $\mathrm{al}^{3}$ used face mask CPAP to extubate an extremely premature infant with cleft lip and palate. They were also successful in extubating the infant to CPAP but we were not successful with NCPAP.
In PIs with cleft lip and palate, BP-NCPAP is a possible mode of noninvasive ventilation.

\section{Conflict of Interest}

The authors declare no conflict of interest.

\section{References}

1 Courtney SE, Barrington KJ. Continuous positive airway pressure and noninvasive ventilation. Clin Perinatol 2007;34(1):73-92, vi

2 Morley CJ, Davis PG. Continuous positive airway pressure: scientific and clinical rationale. Curr Opin Pediatr 2008;20(2):119-124

3 McMahon RM, Bagchi I, Worsey S, Kumararatne B. Use of mask continuous positive airway pressure in a preterm infant presenting with bilateral cleft lip and palate. J Laryngol Otol 2006;120(3): 228-229 